Chapter 18

\title{
Gene Therapy for Primary Immunodeficiencies
}

\author{
Francisco Martin, Alejandra Gutierrez-Guerrero and \\ Karim Benabdellah
}

Additional information is available at the end of the chapter

http://dx.doi.org/10.5772/55594

\section{Introduction}

Primary immunodeficiencies (PID) are caused by mutations in genes involved in the normal development or activity of the immune system [1,2]. PIDs include B- and T-cell defects, phagocytic disorders, and complement deficiencies with the common feature of frequent lifethreatening infections. The phenotypes vary from asymptomatic (IgA deficiency) to severe PIDs (such as Severe combined immunodeficiencies). Treatment of patients with severe PIDs relies in intravenous injection of immunoglobulins, bone marrow transplantation (BMT) and antibiotics. Identical and haploidentical BMT are the only curative treatment, however, the lack of a HLA-matched donor in over $70 \%$ of the patients make necessary the development of new therapeutic strategies $[3,4]$. Gene therapy (GT) could be the best alternative for the treatment of patients with severe PID that lack a HLA-matched donor [5]. The aim of GT strategies is the stable correction of the mutated gene on the patient's own haematopoietic stem cells (HSCs).

The first successful gene therapy clinical trial used gamma-retroviral derived vectors expressing common cytokine-receptor gamma chain $(\gamma \mathrm{c})$ cDNA in HSCs from X-linked severe combined immunodeficiency (SCID-X1) patients [6]. So far, using a very similar vector platform, over 50 PID patients treated with GT can been considered "cured" from SCID-X1, adenosine deaminase deficiency (ADA) and Wiskott-Aldrich syndrome (WAS) PID [7-13]. However, in six children, GT treatment resulted in clonal T-cell proliferation (leukaemia-like disease) [9].

The results obtained in the SCID-X1, ADA and WAS clinical trials clearly showed the importance to improve vector's safety and efficiency $[8,14,15]$. Lentiviral-based vectors have been the vector of choice to enhance efficiency and, at the same time, reduce the side effects of gammaretroviral vectors (see below). Several GT clinical trials for SCID-X1, chronic granu- 
lomatous disease (CGD) and WAS PID using lentiviral vectors (LVs) have started in the last few years.

This chapter intend to illustrate the past, present and near future of GT for the treatment of severe PIDs

\section{Gamma-retroviral vector based gene therapy clinical trials for primary immunodeficiencies}

\subsection{Gammaretrovirus-based vectors}

Gammaretrovirus, also named oncoretrovirus, are efficient, integrative, easy to manipulate and poorly immunogenic. Vector derived for these retroviruses are often named "retroviral vectors" and "oncoretroviral vectors". All the clinical data that will be presented in this section was obtained using a similar gammaretroviral backbone: LTR--- $\psi-----$ transgene------LTR. As consequence the therapeutic gene is expressed through the promoter and enhancer sequences present at the viral LTR. Another common aspect of all the GT strategies presented in this section is the modification of the patient's hematopoietic stem cells (HSCs). However HSCs are quiescent or very slowly dividing cells and gammaretroviral-based vectors require active cell division for transduction [16]. Therefore HSCs transduction protocols require cytokine "pre-stimulation" to induce cell proliferation [17], a process that can modify the characteristics of the haematopoietic precursors [18]. However, since LTR-driven gammaretroviral vectors were the only integrative vectors available at the time, several clinical trials started on SCID$\mathrm{X} 1$, ADA CGD and WAS. An overall conclusion of these clinical trials was that GT is as efficient and safe as haploidentical BMT. However it was also evident the necessity of improving the vector system before GT of PID could be of general use in clinic.

\subsection{X-linked Severe Combined Immunodeficiency (SCID-X1)}

SCID-X1 is a monogenic disease caused by mutations in the interleukin-2 receptor gamma chain gene $(\gamma c)$. Patients with SCID-X1 deficiency do not have T nor NK cells, consequently B-lymphocyte function is also intrinsically compromised [19]. SCID-X1 has been an attractive GT target because patient's cells expressing the transgene have a growth advantage over nonexpressing cells [20,21]. Therefore, GT could, in theory, achieved complete immune reconstitution with a relatively low number of gene-corrected cells. The Fischer group at the "Unité d'Immunologie et d'Hématologie Pédiatriques, Hôpital Necker" in France achieved the first unequivocal success of gene therapy in the two patients treated [6]. The authors transduced patients HSCs (CD34+) with a Murine Leukaemia Virus (MLV) based vector expressing the $\gamma \mathrm{c}$ cDNA following pre-activation with stem cell factor (SCF), polyethylene glycol-megakaryocyte differentiation factor (PG-MDF), IL-3 and Flt3-L. The continuation of this work and other clinical trials in other countries enrolled a total of 20 SCID-X1 patients $[7,8,22,23]$. Between 5 and 12 years after GT, 17 of the 20 treated patients are alive and display full or nearly full correction of the T cell deficiency [24, 25]. The GT treatment led to clear benefits since patients 
recover from ongoing infections with poor prognosis (disseminated infections) and live in a normal environment without evidence of increased susceptibility to infection.

However, 5 of the 20 patients with SCID-X1 on GT trials developed leukaemia 3-6 years after treatment. Four patients were successfully treated with chemotherapy and they are alive and doing well. However the other patient died from chemotherapy-refractory leukemia [26]. This leukaemia-like disease was a result of vector-mediated up-regulation of host cellular oncogenes (i.e. LMO2) [8, 27]. Several studies have demonstrated that MLV-derived vectors integration favour transcriptionally active genes near transcription start sites (TSSs) [28-30]. Leukemogenesis could also be the result of insertional mutagenesis (activation of the LMO2 oncogene) combined with the acquisition of genetic abnormalities unrelated to vector insertion, such as the increase activity of NOTCH1 or the deletion of CDKN2A gene [8].

However, in spite of the secondary effects observed, the results obtained with GT using first generation MLV-based vectors are comparable to those obtained with HLA-identical HSC transplant (HSCT). It is expected that next generation vectors will certainly improve these results as it will discussed later.

\subsection{Adenosine Deaminase (ADA) Severe Combined Immunodeficiency (ADA-SCID)}

ADA-deficiency has been also considered an important target for GT. The ADA gene codify for an enzyme that is expressed in all tissues and catalyses the deamination of 2'-deoxyadenosine and adenosine to 2 'deoxyinosine and inosine. Its absence or malfunction cause the accumulation of purine metabolites that are toxic to the cells. Although the ADA gene is expressed in all tissues, the accumulation of purine metabolites in the immune cells is the main problem. As consequence, ADA patients suffer from lymphopenia, reduced (or absent) cellular and humoral immunity, failure to thrive and recurrent infections. Additionally, the accumulation of purine metabolites in other tissues also produces skeletal, hepatic, renal, lung, and neurologic abnormalities [31, 32]. Like for SCID-X1, bone marrow transplantation (BMT) is the best therapeutic alternative. However, contrary to SCID-X1, there are other treatment options that allow ADA patients to have near-normal lives: Enzyme replacement therapy (ERT) with polyethylene-glycol-conjugated bovine ADA (PEG-ADA). However, although ERT treatment is well tolerated and can partially restore immune function, its effect decline over time and, in addition, lifelong treatment is very expensive[33].

ADA deficiency has been successfully treated by GT using a similar approach to that for SCID$\mathrm{X} 1$, but requiring mild bone-marrow chemoablation [34]. The authors showed immunological and metabolic reconstitution after transplantation of gene-modified CD34 ${ }^{+}$using ADAexpressing-MLV based vectors. The selective growth advantage of ADA-expressing lymphocytes played an important role in the success of this trial. Similar findings have been reported by Gaspar et. al. [23] and again by Aiuti et al[10]. In total, over 40 patients with ADA have been treated in Italy, UK and USA. At present all patients are alive and 29 of them do not require ERT [9, 10, 23, 25, 34-36].

It is important to remark that no leukaemia-like disease have been observed in the ADA-SCID GT trial. The author propose that the differences between SCID-X1 and ADA might be related 
with SCID-X1 genetic background or the role of the therapeutic transgene ( $A D A$ is a housekeeping enzyme whereas $\gamma \mathrm{c}$ is a potential oncogene growth factor receptor). However, in the last clinical trial some non-life threatening adverse effects have been reported such as neutropenia (2 patients), treatment-related infections (2 patients), Epstein-Barr virus reactivations (1 patient) and autoimmune hepatitis (1 patient).

\subsection{X-linked Chronic Granulomatous Disease (X-CGD)}

Chronic granulomatous disease (CGD) is a rare PID characterized by severe, life threatening bacterial and fungal infections. Patients with CGD have also defective degradation of inflammatory mediators leading to granuloma formation. All of these defects are caused by mutations in the nicotinamide adenine dinucleotide phosphate (NADPH) oxidase subunits in phagocytic cells [37]. gp91 phox mutations occur in up to 70\% of the CGD cases and represent the X-linked form of this disorder (X-CGD). Neutrophils, monocytes, macrophages, and eosinophils from CGD patients cannot generate superoxide and other reactive oxygen intermediates to destroy invading bacteria and fungi.

Contrary to SCID-X1 and ADA, CGD is a difficult target for GT, since the expression of the correct form of the gene does not provide selective advantage to hematopoietic progenitors. In addition, myeloid cells have a short life span and therefore a large amount of HSC must be corrected to achieve clinical benefits. Myeloablative conditioning is therefore required to increase the amount of gene-modified cells that engraft into the patients. Several GT clinical trials for CGD have been conducted since 1997. Initial studies using retroviral vector to express p47-phox into CD34+ cells, resulted in low and short-term engraftment of CGD-corrected cells [38]. More recent GT clinical trials on X-CGD conducted in Franckfurt, Zurinch, London, USA and Seoul resulted in higher correction and clinical benefit in several patients. Dr Grez's group showed the most dramatic effects in two children ( 5 and 8 years old) showing recovery from severe pulmonary and spinal aspergillosis. GT treatment also achieved recovery from paraparesis of both legs in one of the children [39]. However, the efficacy was only partial due to a progressive lost of gene-corrected cells over time [39-41]. The lost of transgene expression was, at least in part, due to inactivation of the vector promoter. However, there are other hypothesis that point to the potential toxicity of ectopic expression of gp91 gene on HSCs as a potential cause of the lost of gene-corrected cells [42]. In addition, three patients developed a myelodisplastic syndrome (MDS) due to transactivation of the MDS/EVI oncogene by the retroviral enhancer [40]. The MDS was fatal for two of the patients while the third was treated with HSCTs. These results revealed the importance of developing new, safer and more efficient vectors for GT in CGD.

\subsection{Wiskott-Aldrich Syndrome (WAS)}

Wiskott-Aldrich syndrome (WAS) is a X-linked PID caused by mutation in the WAS gene coding for the Wiskott-Aldrich syndrome protein (WASP), a hematopoietic-specific member of regulators of the actin cytoskeleton $[43,44]$. The most severe form of WAS (where the mutation cause total absence of protein or function) is characterized by recurrent infections, 
microtrombocytopenia, eczema and higher susceptibility to autoimmune diseases and lymphoid malignancies [45].

As for other PID, HLA-identical sibling HSC donor transplantation is considered the treatment of choice (over $80 \%$ survival rate). Allogeneic HSCTs is offering nowadays good outcomes due to improvements in HLA-typing and new alternative donor sources and myeloablative conditioning regimens [46]. However, patients lacking a HLA-matched donor still require alternative therapeutic approaches. In this direction GT could be an alternative in the near future for these patients. In fact WAS is an attractive target for GT since expression of WASP confer selective growth advantage [47-52].

Dr Klein group (Hannover Medical School, Hannover, Germany) performed the first clinical trial for WAS GT [53]. 10 patients were enrolled in this trial and they received autologous $\mathrm{CD}^{+}{ }^{+}$cells transduced with LTR-driven gammaretroviral vectors expressing WASP. All patients received reduced intensity conditioning with Busulfan. Most of the patients treated gain WASP expression in multiple lineages. Platelet counts increased and clinical condition improved with resolution of eczema and bleeding disorder [54, 55]. However, as occurred in the SCID-X1 clinical trials, four out of 10 of the treated patients developed leukaemia [55, 56]. The presence of the strong LTR enhancer and the patient's predisposition to develop lymphomas could favour the high frequency of leukaemia in this trial.

\section{Lentiviral-vector based gene therapy clinical trials for primary immunodeficiencies}

As soon as the first cases of leukaemia appeared in the SCID-X1 GT trial, it was clear that LTRdriven gammaretroviral vectors were not the vector of choice to go further into clinic. Improvements in the gammaretroviral vectors and the design of new integrative vectors became the main goal in the GT field. Several groups have dedicated considerable effort to understand the mechanism of leukomogenesis upon gammaretroviral transduction. The LMO2 oncogene was found in 4/5 cases in the SCID-X1 trial and it is now clear that retrovirus-mediated gene transfer can deregulate proto-oncogene expression through the LTR enhancer activity. With this in mind, Dr. Naldini's group have developed self-inactivated (LTR mutated) lentiviral vectors (based in HIV-1) which have one of the best efficiency/safety ratio [57-59]. LVs, contrary to gammaretroviral vectors are able to achieve efficient transduction of HSCs with minimal activation [60]. They are also safer than gammaretroviral vectors due to their less genotoxic integration site [61-63]. Several clinical trials for PID have started using HIV-1-based vectors and some promising results have already been shown on international meetings. In most cases, the general structure of the vectors is as follow: LTR $\Delta$ U3-- $\psi$----human promoter -----transgene------ LTR $\Delta \mathrm{U} 3$

There are at the moment two GT clinical trials on going for SCID-X1 using lentiviral vectors (http://www.wiley.com/legacy/wileychi/genmed/clinical/). One is designed for newly diagnose children (St Jude Children's Research Hospital) and other is a Phase I/II non-randomized clinical trial designed to treat 13 patients with SCID-X1 who are between 2 and 30 years of age 
and who have clinically significant impairment of immunity. Both cases are based on mice experiments showing a better profile of lentiviral vectors both in term of reconstitution and safety [64].

Dr Gaspar and Dr Kohn have launched two other clinical trials using lentiviral vectors to treat ADA patients in UK and USA respectively. Both groups use EF1 promoter driven lentiviral vectors produced at the same site (Indiana University Vector Production Facility) through a Transatlantic Gene Therapy Consortium. The primary objective of the trial is to examine the safety of the protocol in 10 patients transplanted with LV gene-modified CD $34^{+}$cells. The protocol will involve non-myeloablative conditioning with busulfan and withholding of PEGADA ERT. As secondary objectives the trial will aim for the expression of ADA in peripheral blood leucocytes and immune reconstitution.

CGD is probably the PID where the necessity to improve vector efficiency and safety has been more obvious. The absence of the selective advantage of the gene-modified cells and the short life span of myeloid cells reduce the clinical benefits of gammaretroviral vectors but kept all the secondary effects. In addition, the potential toxicity of ectopic expression of gp91 ${ }^{\text {phox }}$ on HSCs required the use of physiologically regulated vectors [65] expressing the transgene specifically in granulocytes. Very encouraging results have been obtained in animal models using transcriptionally regulated LV $[66,67]$. The first clinical trial for CGD using LV started on November 2011 directed by Adrian Thrasher at Great Ormond Street Hospital for Children (UK). The primary outcome measures will be overall survival but the trial will also study reduction in frequency of infections and long-term immune reconstitution (http://clinicaltrials.gov/ct2/show/NCT01381003].

As SCID-X1 and CGD, GT for WAS has also good reasons to change the therapeutic vectors (see above). There are four clinical trials on going for WAS using LV (FR-0047, UK-0168 and US-1052: journal of gene medicine GT clinical trials data base; NCT01515462: Clincaltrial.gov). All trials will use a similar construct which drive the expression of the WASP cDNA through its own promoter. The WASp-promoter-driven LVs are haematopoietic-specific [47, 49, 68], physiological $[49,69]$ and avoid deleterious effects of over-expression in non-target cells[70]. Preliminary data presented at the 20th European Society of Gene and Cell Therapy by the Italian and French groups showed impressive results both, in terms of immune reconstitution and safety profile. It is important to note that integration site analysis in these patients did not show any preference for the proto-oncongens LMO2 or EVI1. In addition they didn't observe, at the time of analysis, any evidence of clonal dominance (usually indicative of proto-oncogenes activation).

\section{Future directions}

Based on the data shown, it does appear that new generation LVs driving the expression of the transgene through physiological promoters could be a big step toward GT clinical translation. Exciting results are expected on the clinical trials undergoing at the moment. Still, LV integrates randomly at active sites in the cell genome and can therefore alter its normal 
expression pattern. New, undesired side effects could appear in the future. New vectors must still consider improving two safety aspects: 1- genotoxicity (genomic alteration due to vector integrations) and 2- ectopic/unregulated expression of the transgene. Strategies to minimize or eliminate genotoxicity problems can be grouped in those based in improving retroviral vectors and those based in the development of non-viral technologies such as gene editing (revised in [14, 65]).

\section{Acknowledgements}

This work has been financed by Fondo de Investigaciones Sanitarias ISCIII (Spain) and Fondo Europeo de Desarrollo Regional (FEDER) from the European Union, through the research grant № PS09/00340, by the Consejería de Innovación Ciencia y Empresa (grants № P09CTS-04532 and PAIDI-Bio-326) and Consejería de Salud (grant № PI0001/2009) from the Junta de Andalucía and FEDER/ Fondo de Cohesion Europeo (FSE) de Andalucía 2007-2013 to F.M.

\section{Author details}

Francisco Martin*, Alejandra Gutierrez-Guerrero and Karim Benabdellah

*Address all correspondence to: francisco.martin@genyo.es

Gene and Cell Therapy Group. Human DNA variability department. GENYO. Centre for Genomics and Oncological Research: Pfizer, University of Granada, Andalusian Regional Government. Parque Tecnológico Ciencias de la Salud (PTCS), Granada, Spain

\section{References}

[1] Marodi L, Notarangelo LD. Immunological and genetic bases of new primary immunodeficiencies. Nat Rev Immunol. 2007 Nov;7(11):851-61.

[2] Pessach I, Walter J, Notarangelo LD. Recent advances in Primary Immunodeficiencies: identification of novel genetic defects and unanticipated phenotypes. Pediatric research. 2009 Jan 28.

[3] Filipovich A. Hematopoietic cell transplantation for correction of primary immunodeficiencies. Bone Marrow Transplant. 2008 Aug;42 Suppl 1:S49-S52.

[4] Neven B, Leroy S, Decaluwe H, Le Deist F, Picard C, Moshous D, et al. Long-term outcome after hematopoietic stem cell transplantation of a single-center cohort of 90 patients with severe combined immunodeficiency. Blood. 2009 Apr 23;113(17): 4114-24. 
[5] Kildebeck E, Checketts J, Porteus M. Gene therapy for primary immunodeficiencies. Curr Opin Pediatr. 2012 Dec;24(6):731-8.

[6] Cavazzana-Calvo M, Hacein-Bey S, de Saint Basile G, Gross F, Yvon E, Nusbaum P, et al. Gene therapy of human severe combined immunodeficiency (SCID)-X1 disease. Science. 2000;288(5466):669-72.

[7] Cavazzana-Calvo M, Lagresle C, Hacein-Bey-Abina S, Fischer A. Gene therapy for severe combined immunodeficiency. Annu Rev Med. 2005;56:585-602.

[8] Howe SJ, Mansour MR, Schwarzwaelder K, Bartholomae C, Hubank M, Kempski H, et al. Insertional mutagenesis combined with acquired somatic mutations causes leukemogenesis following gene therapy of SCID-X1 patients. J Clin Invest. 2008 Sep 2;118(9):3143-50.

[9] Fischer A, Cavazzana-Calvo M. Gene therapy of inherited diseases. Lancet. 2008 Jun 14;371(9629):2044-7.

[10] Aiuti A, Cattaneo F, Galimberti S, Benninghoff U, Cassani B, Callegaro L, et al. Gene therapy for immunodeficiency due to adenosine deaminase deficiency. $\mathrm{N}$ Engl J Med. 2009 Jan 29;360(5):447-58.

[11] Ott MG, Schmidt M, Schwarzwaelder K, Stein S, Siler U, Koehl U, et al. Correction of $\mathrm{X}$-linked chronic granulomatous disease by gene therapy, augmented by insertional activation of MDS1-EVI1, PRDM16 or SETBP1. Nat Med. 2006 Apr;12(4):401-9.

[12] Boztug K, Schmidt M, Schwarzer A, Banerjee PP, Diez IA, Dewey RA, et al. Stem-cell gene therapy for the Wiskott-Aldrich syndrome. N Engl J Med. 2010 Nov 11;363(20): 1918-27.

[13] Galy A, Thrasher AJ. Gene therapy for the Wiskott-Aldrich syndrome. Curr Opin Allergy Clin Immunol. 2011 Dec;11(6):545-50.

[14] Romero Z, Toscano MG, Unciti JD, Molina I, Martin F. Safer Vectors For Gene Therapy Of Primary Immunodeficiencies. Curr Gene Ther. 2009 Aug 1.

[15] Toscano MG, Romero Z, Munoz P, Cobo M, Benabdellah K, Martin F. Physiological and tissue-specific vectors for treatment of inherited diseases. Gene Ther. 2011 Feb; 18(2):117-27.

[16] Miller DG, Adam MA, Miller AD. Gene transfer by retrovirus vectors occurs only in cells that are actively replicating at the time of infection. Mol Cell Biol. 1990 Aug; 10(8):4239-42.

[17] Demaison C, Brouns G, Blundell MP, Goldman JP, Levinsky RJ, Grez M, et al. A defined window for efficient gene marking of severe combined immunodeficient-repopulating cells using a gibbon ape leukemia virus-pseudotyped retroviral vector. Hum Gene Ther. 2000;11(1):91-100. 
[18] Baum C, Dullmann J, Li Z, Fehse B, Meyer J, Williams DA, et al. Side effects of retroviral gene transfer into hematopoietic stem cells. Blood. 2003 Mar 15;101(6):2099-114.

[19] Noguchi M, Yi H, Rosenblatt HM, Filipovich AH, Adelstein S, Modi WS, et al. Interleukin-2 receptor gamma chain mutation results in $X$-linked severe combined immunodeficiency in humans. Cell. 1993 Apr 9;73(1):147-57.

[20] Stephan V, Wahn V, Le Deist F, Dirksen U, Broker B, Muller-Fleckenstein I, et al. Atypical X-linked severe combined immunodeficiency due to possible spontaneous reversion of the genetic defect in T cells. N Engl J Med. 1996 Nov 21;335(21):1563-7.

[21] Hacein-Bey-Abina S, Fischer A, Cavazzana-Calvo M. Gene therapy of X-linked severe combined immunodeficiency. Int J Hematol. 2002 Nov;76(4):295-8.

[22] Hacein-Bey-Abina S, Le Deist F, Carlier F, Bouneaud C, Hue C, De Villartay JP, et al. Sustained correction of $\mathrm{X}$-linked severe combined immunodeficiency by ex vivo gene therapy. N Engl J Med. 2002 Apr 18;346(16):1185-93.

[23] Gaspar HB, Bjorkegren E, Parsley K, Gilmour KC, King D, Sinclair J, et al. Successful reconstitution of immunity in ADA-SCID by stem cell gene therapy following cessation of PEG-ADA and use of mild preconditioning. Mol Ther. 2006 Oct;14(4):505-13.

[24] Hacein-Bey-Abina S, Hauer J, Lim A, Picard C, Wang GP, Berry CC, et al. Efficacy of gene therapy for X-linked severe combined immunodeficiency. N Engl J Med. 2010 Jul 22;363(4):355-64.

[25] Gaspar HB, Cooray S, Gilmour KC, Parsley KL, Adams S, Howe SJ, et al. Long-term persistence of a polyclonal $\mathrm{T}$ cell repertoire after gene therapy for X-linked severe combined immunodeficiency. Sci Transl Med. 2011 Aug 24;3(97):97ra79.

[26] Hacein-Bey-Abina S, Garrigue A, Wang GP, Soulier J, Lim A, Morillon E, et al. Insertional oncogenesis in 4 patients after retrovirus-mediated gene therapy of SCID-X1. J Clin Invest. 2008 Sep;118(9):3132-42.

[27] Hacein-Bey-Abina S, von Kalle C, Schmidt M, Le Deist F, Wulffraat N, McIntyre E, et al. A serious adverse event after successful gene therapy for X-linked severe combined immunodeficiency. N Engl J Med. 2003 Jan 16;348(3):255-6.

[28] Wu X, Li Y, Crise B, Burgess SM. Transcription start regions in the human genome are favored targets for MLV integration. Science. 2003 Jun 13;300(5626):1749-51.

[29] Laufs S, Nagy KZ, Giordano FA, Hotz-Wagenblatt A, Zeller WJ, Fruehauf S. Insertion of retroviral vectors in NOD/SCID repopulating human peripheral blood progenitor cells occurs preferentially in the vicinity of transcription start regions and in introns. Mol Ther. 2004 Nov;10(5):874-81.

[30] Bushman F, Lewinski M, Ciuffi A, Barr S, Leipzig J, Hannenhalli S, et al. Genomewide analysis of retroviral DNA integration. Nat Rev Microbiol. 2005 Nov;3(11): 848-58. 
[31] Ratech H, Hirschhorn R, Greco MA. Pathologic findings in adenosine deaminase deficient-severe combined immunodeficiency. II. Thymus, spleen, lymph node, and gastrointestinal tract lymphoid tissue alterations. Am J Pathol. 1989 Dec;135(6): $1145-56$.

[32] Rogers MH, Lwin R, Fairbanks L, Gerritsen B, Gaspar HB. Cognitive and behavioral abnormalities in adenosine deaminase deficient severe combined immunodeficiency. J Pediatr. 2001 Jul;139(1):44-50.

[33] Gaspar HB, Aiuti A, Porta F, Candotti F, Hershfield MS, Notarangelo LD. How I treat ADA deficiency. Blood. 2009 Oct 22;114(17):3524-32.

[34] Aiuti A, Slavin S, Aker M, Ficara F, Deola S, Mortellaro A, et al. Correction of ADASCID by stem cell gene therapy combined with nonmyeloablative conditioning. Science. 2002 Jun 28;296(5577):2410-3.

[35] Sakiyama Y, Ariga T, Ohtsu M. [Gene therapy for adenosine deaminase deficiency]. Nippon Rinsho. 2005 Mar;63(3):448-52.

[36] Aiuti A, Cassani B, Andolfi G, Mirolo M, Biasco L, Recchia A, et al. Multilineage hematopoietic reconstitution without clonal selection in ADA-SCID patients treated with stem cell gene therapy. J Clin Invest. 2007 Aug;117(8):2233-40.

[37] Seger RA. Modern management of chronic granulomatous disease. Br J Haematol. 2008 Feb;140(3):255-66.

[38] Malech HL, Maples PB, Whiting-Theobald N, Linton GF, Sekhsaria S, Vowells SJ, et al. Prolonged production of NADPH oxidase-corrected granulocytes after gene therapy of chronic granulomatous disease. Proc Natl Acad Sci U S A. 1997 Oct 28;94(22): 12133-8.

[39] Grez M, Reichenbach J, Schwable J, Seger R, Dinauer MC, Thrasher AJ. Gene therapy of chronic granulomatous disease: the engraftment dilemma. Mol Ther. 2011 Jan; 19(1):28-35.

[40] Stein S, Ott MG, Schultze-Strasser S, Jauch A, Burwinkel B, Kinner A, et al. Genomic instability and myelodysplasia with monosomy 7 consequent to EVI1 activation after gene therapy for chronic granulomatous disease. Nat Med. 2010 Feb;16(2):198-204.

[41] Kuhns DB, Alvord WG, Heller T, Feld JJ, Pike KM, Marciano BE, et al. Residual NADPH oxidase and survival in chronic granulomatous disease. N Engl J Med. 2010 Dec 30;363(27):2600-10.

[42] Bedard K, Krause KH. The NOX family of ROS-generating NADPH oxidases: physiology and pathophysiology. Physiol Rev. 2007 Jan;87(1):245-313.

[43] Gallego MD, Santamaria M, Pena J, Molina IJ. Defective actin reorganization and polymerization of Wiskott-Aldrich $\mathrm{T}$ cells in response to CD3-mediated stimulation. Blood. 1997;90(8):3089-97. 
[44] Ochs HD, Thrasher AJ. The Wiskott-Aldrich syndrome. J Allergy Clin Immunol. 2006 Apr;117(4):725-38; quiz 39.

[45] Bosticardo M, Marangoni F, Aiuti A, Villa A, Roncarolo MG. Recent advances in understanding the pathophysiology of Wiskott-Aldrich syndrome. Blood. 2009 Apr 7.

[46] Moratto D, Giliani S, Bonfim C, Mazzolari E, Fischer A, Ochs HD, et al. Long-term outcome and lineage-specific chimerism in 194 patients with Wiskott-Aldrich syndrome treated by hematopoietic cell transplantation in the period 1980-2009: an international collaborative study. Blood. 2011 Aug 11;118(6):1675-84.

[47] Dupre L, Trifari S, Follenzi A, Marangoni F, Lain de Lera T, Bernad A, et al. Lentiviral vector-mediated gene transfer in T cells from Wiskott-Aldrich syndrome patients leads to functional correction. Mol Ther. 2004 Nov;10(5):903-15.

[48] Konno A, Wada T, Schurman SH, Garabedian EK, Kirby M, Anderson SM, et al. Differential contribution of Wiskott-Aldrich syndrome protein to selective advantage in T- and B-cell lineages. Blood. 2004 Jan 15;103(2):676-8.

[49] Martin F, Toscano MG, Blundell M, Frecha C, Srivastava GK, Santamaria M, et al. Lentiviral vectors transcriptionally targeted to hematopoietic cells by WASP gene proximal promoter sequences. Gene Ther. 2005 Apr;12(8):715-23.

[50] Ariga T, Kondoh T, Yamaguchi K, Yamada M, Sasaki S, Nelson DL, et al. Spontaneous in vivo reversion of an inherited mutation in the Wiskott-Aldrich syndrome. J Immunol. 2001 Apr 15;166(8):5245-9.

[51] Wada T, Konno A, Schurman SH, Garabedian EK, Anderson SM, Kirby M, et al. Second-site mutation in the Wiskott-Aldrich syndrome (WAS) protein gene causes somatic mosaicism in two WAS siblings. J Clin Invest. 2003 May;111(9):1389-97.

[52] Wada T, Schurman SH, Otsu M, Garabedian EK, Ochs HD, Nelson DL, et al. Somatic mosaicism in Wiskott--Aldrich syndrome suggests in vivo reversion by a DNA slippage mechanism. Proc Natl Acad Sci U S A. 2001 Jul 17;98(15):8697-702.

[53] Boztug K, Dewey RA, Klein C. Development of hematopoietic stem cell gene therapy for Wiskott-Aldrich syndrome. Curr Opin Mol Ther. 2006 Oct;8(5):390-5.

[54] Boztug K, Schmidt M, Schwarzer A, Banerjee PP, Diez IA, Dewey RA, et al. Stem-cell gene therapy for the Wiskott-Aldrich syndrome. N Engl J Med. 2010 Nov 11;363(20): 1918-27.

[55] Corrigan-Curay J, Cohen-Haguenauer O, O'Reilly M, Ross SR, Fan H, Rosenberg N, et al. Challenges in vector and trial design using retroviral vectors for long-term gene correction in hematopoietic stem cell gene therapy. Mol Ther. 2012 Jun;20(6):1084-94.

[56] Avedillo Diez I, Zychlinski D, Coci EG, Galla M, Modlich U, Dewey RA, et al. Development of novel efficient SIN vectors with improved safety features for Wiskott-Aldrich syndrome stem cell based gene therapy. Mol Pharm. 2011 Oct 3;8(5):1525-37. 
[57] Montini E, Cesana D, Schmidt M, Sanvito F, Ponzoni M, Bartholomae C, et al. Hematopoietic stem cell gene transfer in a tumor-prone mouse model uncovers low genotoxicity of lentiviral vector integration. NatBiotechnol. 2006;24(6):687-96.

[58] Zufferey R, Dull T, Mandel RJ, Bukovsky A, Quiroz D, Naldini L, et al. Self-inactivating lentivirus vector for safe and efficient in vivo gene delivery. J Virol. 1998;72(12): 9873-80.

[59] Naldini L, Blomer U, Gallay P, Ory D, Mulligan R, Gage FH, et al. In vivo gene delivery and stable transduction of nondividing cells by a lentiviral vector. Science. 1996;272(5259):263-7.

[60] Case SS, Price MA, Jordan CT, Yu XJ, Wang L, Bauer G, et al. Stable transduction of quiescent CD34(+)CD38(-) human hematopoietic cells by HIV-1-based lentiviral vectors. Proc Natl Acad Sci U S A. 1999 Mar 16;96(6):2988-93.

[61] Montini E, Cesana D, Schmidt M, Sanvito F, Ponzoni M, Bartholomae C, et al. Hematopoietic stem cell gene transfer in a tumor-prone mouse model uncovers low genotoxicity of lentiviral vector integration. Nat Biotechnol. 2006 Jun;24(6):687-96.

[62] Gonzalez-Murillo A, Lozano ML, Montini E, Bueren JA, Guenechea G. Unaltered repopulation properties of mouse hematopoietic stem cells transduced with lentiviral vectors. Blood. 2008 Aug 6.

[63] Montini E, Cesana D, Schmidt M, Sanvito F, Bartholomae CC, Ranzani M, et al. The genotoxic potential of retroviral vectors is strongly modulated by vector design and integration site selection in a mouse model of HSC gene therapy. J Clin Invest. 2009 Apr;119(4):964-75.

[64] Zhou S, Mody D, DeRavin SS, Hauer J, Lu T, Ma Z, et al. A self-inactivating lentiviral vector for SCID-X1 gene therapy that does not activate LMO2 expression in human $\mathrm{T}$ cells. Blood. 2010 Aug 12;116(6):900-8.

[65] Toscano MG, Romero Z, Munoz P, Cobo M, Benabdellah K, Martin F. Physiological and tissue-specific vectors for treatment of inherited diseases. Gene Ther. 2011 Feb; 18(2):117-27.

[66] Santilli G, Almarza E, Brendel C, Choi U, Beilin C, Blundell MP, et al. Biochemical correction of X-CGD by a novel chimeric promoter regulating high levels of transgene expression in myeloid cells. Mol Ther. 2011 Jan;19(1):122-32.

[67] Barde I, Laurenti E, Verp S, Wiznerowicz M, Offner S, Viornery A, et al. Lineage- and stage-restricted lentiviral vectors for the gene therapy of chronic granulomatous disease. Gene Ther. 2011 Nov;18(11):1087-97.

[68] Frecha C, Toscano MG, Costa C, Saez-Lara MJ, Cosset FL, Verhoeyen E, et al. Improved lentiviral vectors for Wiskott-Aldrich syndrome gene therapy mimic endogenous expression profiles throughout haematopoiesis. Gene Ther. 2008 Jun;15(12): 930-41. 
[69] Charrier S, Dupre L, Scaramuzza S, Jeanson-Leh L, Blundell MP, Danos O, et al. Lentiviral vectors targeting WASp expression to hematopoietic cells, efficiently transduce and correct cells from WAS patients. Gene Ther. 2007 Mar;14(5):415-28.

[70] Toscano MG, Frecha C, Benabdellah K, Cobo M, Blundell M, Thrasher AJ, et al. Hematopoietic-specific lentiviral vectors circumvent cellular toxicity due to ectopic expression of Wiskott-Aldrich syndrome protein. Hum Gene Ther. 2008 Feb;19(2): 179-97. 
